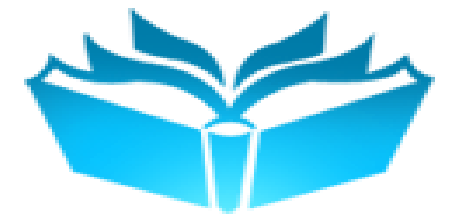 \\ I JRDET
}

International Journal of Recent Development in Engineering and Technology

Website: www.ijrdet.com (ISSN 2347-6435 (Online)) Volume 10, Issue 1, June 2021)

Manuscript Received: 10 Feb 2021, Received in Revised Form: 12 May 2021, Accepted: 16 June 2021 DOI: 10.54380/IJRDETV10I103

\section{Piezoelectric Insole}

\author{
Mallikarjun Mudda ${ }^{1}$, Kotte Nived Maanyu ${ }^{2}$, Dasa Goutham Raj ${ }^{3}$, R Vamshi Krishna ${ }^{4}$ \\ ${ }^{1}$ Associate Professor, Department of Electronics and Communication Engg., Sreenidhi Institute of Science \& Technology, India, \\ ${ }^{2,3,4}$ Students of Department of Electronics and Communication Engineering, Sreenidhi Institute of Science and Technology, India
}

\begin{abstract}
Envisaged research planned so as to turn the kinetic energy generated by walking into power, which is then deposited in a compact battery pack, into a shoe insole. Health has been on the edge because of our hectic and torpid lives. Here we address a system utilizing piezoelectric material that furnishes mobile devices as an alternate means of powering etc. It can also be meant for emergency lighting applications such as flashlights and emergency torch.
\end{abstract}

\section{INTRODUCTION}

The friction is applied on the earth as a human moves and this strain can be transformed into electrical energy that can be used for driving electronic devices. A Mobile Charging System is built in this article. In the shoe is placed a piezoelectric generator. The power which the piezoelectric generator produces while a person moves.Therefore in this way we can observe a clean generation of energy using our daily activities which cost nothing but a small installation of gadgets, while at the same time maintaining our safety.

A shoe has two locations where the greatest pressure applied is the heel and the foot, and this is the precise position of the piezoelectric unit. The architecture is composed of a pair of piezoelectric units linked in order. In a linear system, the front panel has the series of piezoelectric generators, and the back panel has a circular design. The receiving and charging side collects intermittent or continuous energy input from the piezo generator and efficiently stores its energy in the capacitor bank.

\section{Piezoelectricity:}

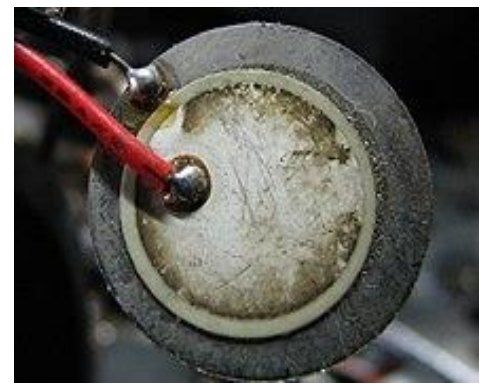

Figure 1. Piezoeletric Disc
A piezoelectric sensor is a device that uses the piezoelectric effect, to measure changes in pressure, acceleration, temperature, strain, or force by converting them to an electrical charge. The prefix piezo- is Greek for 'press' or 'squeeze'.Piezoelectricity is the electric charge that accumulates in certain solid materials (such as crystals, certain ceramics, and biological matter such as bone, DNA and various proteins) in response to applied mechanical stress. The word piezoelectricity means electricity resulting from pressure and latent heat.

The piezoelectric effect results from the linear electromechanical interaction between the mechanical and electrical states in crystalline materials with no inversion symmetry.[5] The piezoelectric effect is a reversible process: materials exhibiting the piezoelectric effect (the internal generation of electrical charge resulting from an applied mechanical force) also exhibit the reverse piezoelectric effect, the internal generation of a mechanical strain resulting from an applied electrical field.

Based on piezoelectric technology various physical quantities can be measured the most common are pressure and acceleration. For pressure sensors, a thin membrane and a massive base are used, ensuring that an applied pressure specifically loads the elements in one direction. For accelerometers, a seismic mass is attached to the crystal elements. When the accelerometer experiences a motion, the invariant seismic mass loads the elements according to Newton's second law of motion $\mathrm{F}=\mathrm{m}$ a $\{$ displaystyle $\mathrm{F}=\mathrm{ma}\}$.

\section{LITERACY SURVEY}

Many attempts have been made in the past to tap the mechanical force associated with walking, leading to the consideration of a host of technologies ranging from the construction of various electromechanical generators to the surgical placement of piezoelectric material in animals .No system to date has served all of the needs of the wearable power generating system - lightweight, minimum effort, high power generation, convenient power delivery, and good power regulation. Previously, there has been a limited 


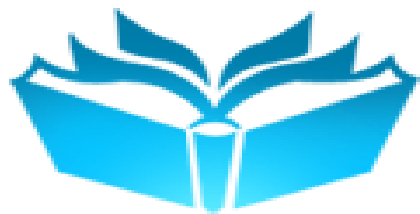 \\ I IRD ET \\ International Journal of Recent Development in Engineering and Technology \\ Website: www.ijrdet.com (ISSN 2347-6435 (Online)) Volume 10, Issue 1, June 2021) \\ Manuscript Received: 10 Feb 2021, Received in Revised Form: 12 May 2021, Accepted: 16 June 2021 DOI: 10.54380/IJRDETV10I103}

amount of piezoelectric, energy-harvested, shoe-mounted bio-sensing systems.

However, there has been research on energy-harvesting using piezoelectrics. Stacy Morris of MIT developed a wireless, shoe-based, gait analysis system. The system utilized Force-sensitive resistors (FSRs) and PVDF transducers for sensing both static and dynamic forces.Responsive Environments Group at the MIT Media Laboratory created a system that utilized the energy harvested from two piezo transducers to broadcast RFID signals. Another system by Patrick Chirang, IEEE Member, supports energy capture from multiple excitation sources, which harvest energy from both pressure and bending. It uses two separate material configurations, one near the heel for pressure and the other along the length of the foot for bending movements. Thus, maximizing energy capture. Once this energy was captured the issue to harvest it arose. This paper presented us with a technique to store the energy generated. While their solution uses COTS piezoelectric harvesters, there are many other methods for energy harvesting. It provides a survey of some different methods, including electromagnetic, electrostatic, and more. Additionally, presents a shoe-based energyharvesting method using di-electric elastomers achieving $120 \mathrm{~m}$ amps per step. They chose piezoelectric harvesters due to their COTS availability, small form-factor, and potential for mechanical energy capture. They've demonstrated a podiatric sensing shoe system that is powered completely by the movement of the wearer. Offthe-shelf electronics are used for energy-harvesting capability, and to obtain distribution data of foot pressure. Their system is also vertically integrated, including not only the hardware but also the coordinated visualization and database back-end since piezoelectric transducers produce electrical energy only by physical deflection, they sought to harness energy from both foot strikes and bending, using one rigid transducer and one flexible. Their ultimate goal was to capture otherwise wasted energy generated by the natural movements of walking, running, and general athletic activity. The complete prototype, including the energy harvesting and power circuitry, was able to sufficiently power the shoe system at different sensor capture rates, depending on the activity of the wearer.
As it is, this paper focused mainly on podiatric sensing performed in order to obtain precise medical analysis. Another paper on New Energy Harvesting Systems proposes a ShoePower Generator using Piezoelectricitynew arrangement of four piezoelectric ceramic plates. The piezoelectric transducer used is the conventional piezoceramic material. They have realized a piezoelectric transducer for which a $\mathrm{PZT}+\mathrm{Nb}$ piezoelectric ceramic element was used for low energy source build with piezoelectric circular and linear transducers. The ceramic element has the shape of a disk whose piezoelectric properties are previously known. These were designed in a circular shape and mounted on circular copper plates. Due to their electric proprieties and small size, the piezoelectric linear transducers can be used in energy harvesting systems applications. The other design consisted of two longer plates as bases. On the same plate ceramic piezoelectric material is made of four identical areas, thus highlighting electric potential differences corresponding to each zone as a result of the takeover of vibration energy. They highlight electric potential difference corresponding to each zone's applied stress. The other plate is coated uniformly and can be used for reference terminal (ground), while each of the four rectangular patches can be connected to an individual electrode. If the deformation of the ceramic plate is not uniform the electrodes might take different potential values and the piezo ceramic plate becomes an electrical generator with four different output voltages. If the plate is rigid and the deformations are identical, the four terminals provide equal output voltages. A multi-physics numerical simulation further illustrates such a piezoelectric transducer operation. The numerical model was built and analyzed with Comsol Multi-physics. The software has multiple postprocessing functions, allowing the simulation of a testing program and the extraction of miscellaneous information, which cannot be always obtained by measurements on a physical model. By introducing a summing electronic block, as a part of system energy harvesting, can effectively take power from four piezoelectric transducers elements, simultaneously. 


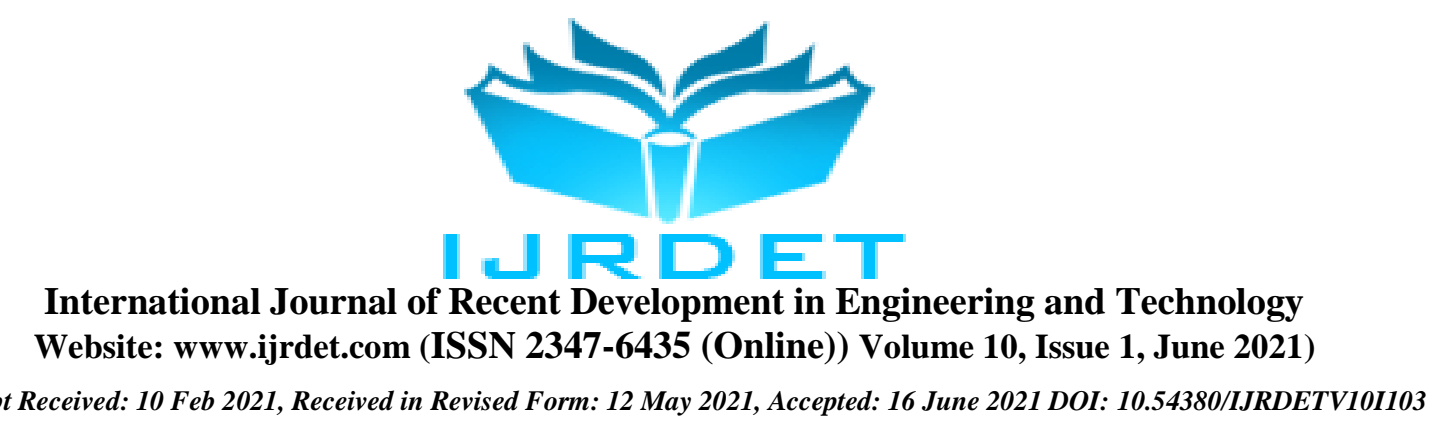

III. Proposed System AND Methodology

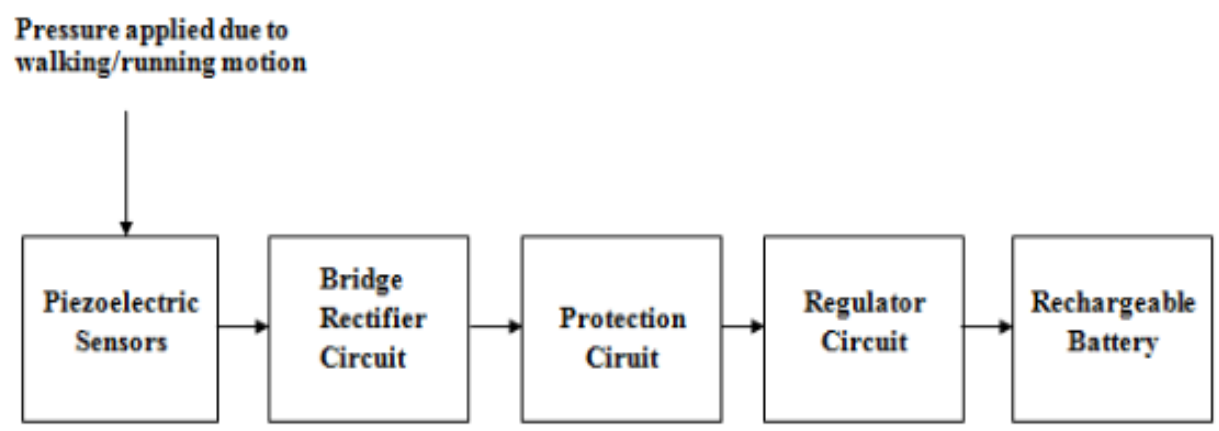

Figure 2: Proposed System Block Daigram

Essentially, the main power source that makes this project possible is something called a piezoelectric transducer. Piezoelectric transducers, or piezo elements, are comprised of materials such as crystals and certain ceramics that have a special property that allows them to convert physical energy into AC electricity.
Fortunately, we can take advantage of this special property by putting piezo elements underneath our feet in such a way that every time we take a step, we are using our weight to push on the piezoelectric elements- which then, in turn, convert that energy into electricity. The only issue with this, however, is that we need DC, not AC to power our stuff. We can solve this problem by creating a bridge rectifier with diodes to convert the $\mathrm{AC}$ power to $\mathrm{DC}$ power we can use.

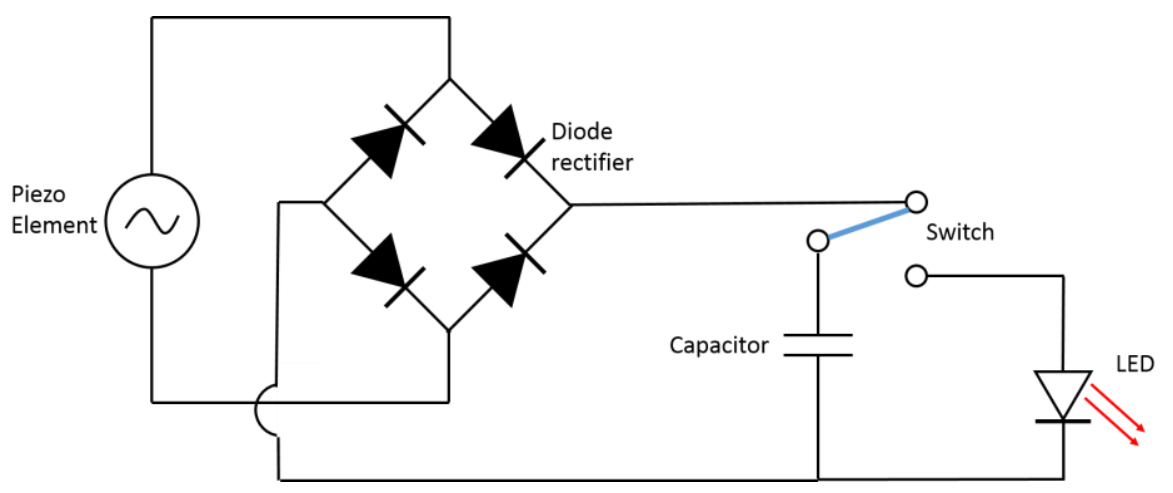

Figure 3: Bridge Rectifier Circiut

We can solve this issue by wiring all the piezo elements in parallel (in other words, the positives are always soldered to each other and the negatives are always soldered to each other). In this way, we will be able to increase the number of amps and consequently charge our devices faster.

Once all of the piezo elements on the heel piece are wired in parallel, solder the last piezo in the chain to one of the piezo elements on the toe piece, and continue to solder the piezo in parallel until all 14 elements are connected.
When a force is applied on piezo material, a charge is generated across it. Thus, it can be assumed to be an ideal capacitor. Thus, all equations governing capacitors can be applied to it. In this project, on one tile, we connect 3 piezo in series.10 such series connections are connected in parallel. Thus when 3 piezoelectric discs are connected in series, its equivalent capacitance becomes: 


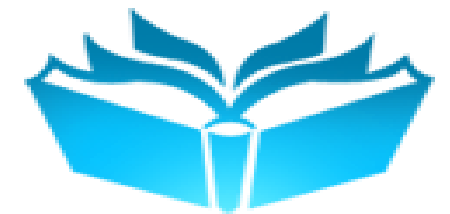 \\ I IRDET}

International Journal of Recent Development in Engineering and Technology

Website: www.ijrdet.com (ISSN 2347-6435 (Online)) Volume 10, Issue 1, June 2021)

Manuscript Received: 10 Feb 2021, Received in Revised Form: 12 May 2021, Accepted: 16 June 2021 DOI: 10.54380/IJRDETV10I103

$1 / \mathrm{Ceq}=1 / \mathrm{C} 1+1 / \mathrm{C} 2+1 / \mathrm{C} 3------------(\mathrm{i})$

We know, $\mathrm{Q}=\mathrm{C} * \mathrm{~V}$ (ii) So, $\mathrm{C}=\mathrm{Q} / \mathrm{V}$--------- (iii)

Hence, Veq = V1/Q + V2/Q + V3/Q-------- (iv)

Thus, Veq = V1 + V2 + V3---------- (v)

\section{Components required}

1. Soles

2. Piezoelectric elements

3. Rechargeable battery

4. Soldering iron + solder

5. Double-sided tape

6. 1n4001 - 1N4007 Diodes

7. Multimeter

8. Shoe

\section{Piezoelectric Transducer Applications}

- As piezoelectric materials cannot measure static values these are primarily used for measuring surface roughness, in accelerometers and as a vibration pickup.

- They are used in seismographs to measure vibrations in rockets.

- In strain gauges to measure force, stress, vibrations, etc...

- Used by automotive industries to measure detonations in engines.

- These are used in ultrasonic imaging in medical applications.

\section{Advantages and Limitations}

- These are active transducer i.e. they don't require external power for working and are therefore selfgenerating.

- The high-frequency response of these transducers makes a good choice for various applications.

- Temperature and environmental conditions can affect the behavior of the transducer.

- They can only measure changing pressure hence they are useless while measuring static parameters.

\section{RESUlts AND Discussion}

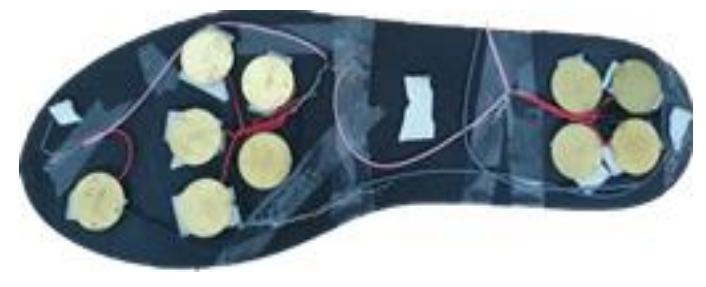

There are several methods available to integrate energy generating elements harvesting human energy and movement, piezoelectric materials associated with electrostatic generators seem to be one of the most promising elements. In particular, electro-active, polymers are particularly interesting due to their low cost, flexibility, and easy integration into elements such as clothes and shoes. We can conclude that we have successfully generated electricity to charge a device such as a mobile phone using piezoelectricity. This can produce energy which is possible for a person of every age group. It is a positive step towards green technology which is to be essential nowadays.

Currently, industrial and manufacturing is the largest application market for piezoelectric devices, followed by the automotive industry. Strong demand also comes from medical instruments as well as in telecommunications. The global demand for piezoelectric devices was valued at approximately US $\$ 14.8$ billion in 2010. The largest material group for piezoelectric devices is piezo-ceramics, and piezo-polymer is experiencing the fastest growth due to its low weight and small size.

\section{CONCLUSION}

Piezoelectric materials can be placed under the floor of various busy areas and can be used as a renewable energy source for lighting systems present around. It can also be placed under the floor of discotheque as a large amount of pressure is applied on the floor while jumping. The future scope of our project is extremely good. It can be applied in any place where ever there is mechanical stress is in the picture.This humanitarian project holds the solution to the problem almost every smartphone faces. Around 1.8 Billion people use smartphones, and almost every smartphone user wishes he had more battery and a way to charge it anytime. This research Project holds the key to an uninterrupted way of using smartphones.Harvesting energy from human motions is an attractive approach for obtaining clean and sustainable energy. This project has its roots in all the areas of consumer electronics. This project also 


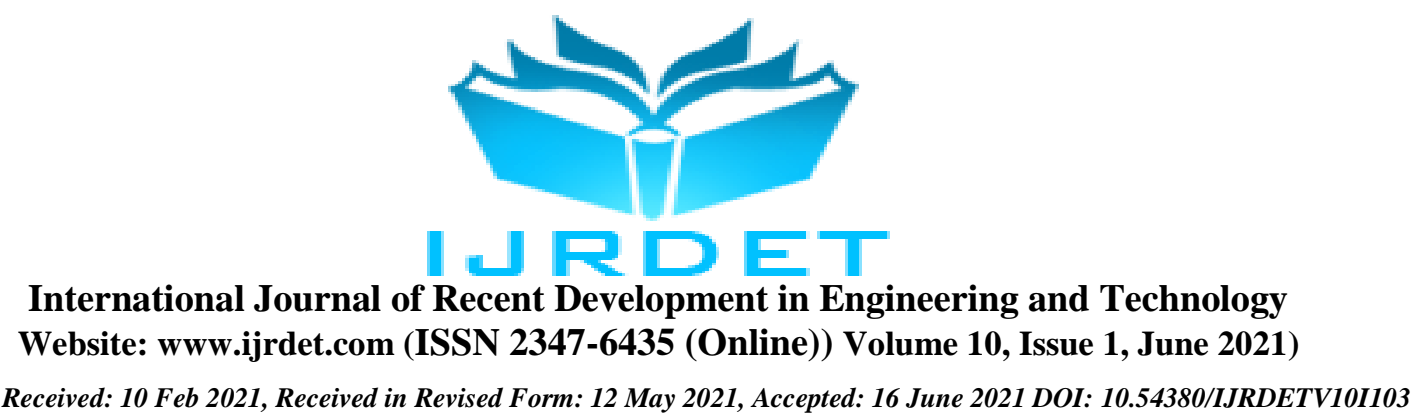

extends Future work includes designing, authentication and monitoring systems for this project.

\section{REFERENCES}

[1] B. Steele, "Timed walking tests of exercise capacity in chronic cardiopulmonary illness," J. Cardiopulm. Rehabil. Prev., vol. 16, no. 1, pp. 25-33, 1996.

[2] S. Roundy, P. K. Wright, and J. Rabaey, "A study of low-level vibrations as a power source for wireless sensor nodes," Comput. Commun., vol. 26, no. 11, pp. 1131-1144, 2003.

[3] P. D. Mitcheson, E. M. Yeatman, G. K. Rao, A. S. Holmes, and T. C. Green, "Energy harvesting from human and machine motion for wireless electronic devices," Proc. IEEE, vol. 96, no. 9, pp. 14571486, 2008.

[4] Bamberg, S.J.M.; Benbasat, A.Y.; Scarborough, D.M.; Krebs, D.E.; Paradiso, J.A., "Gait Analysis Using a Shoe-Integrated Wireless Sensor System," Information Technology in Biomedicine, IEEE Transactions on, vol.12, no.4, pp.413,423, July 2008.

[5] Shenck, N.S.; Paradiso, J.A., "Energy scavenging with shoemounted piezoelectrics," Micro, IEEE, vol.21, no.3, pp.30,42, May/Jun 2001.

[6] Patrick C, Meier R, Nicholas Kelly, Almog O, “ A Piezoelectric Energy Harvesting Shoe System For Podiatric Sensing" by Student Member sand Members of IEEE, January 2015.

[7] Lucian P.D, Laurentiu C.L, Ioana P, Ilina D.I, "New Energy Harvesting Systems Designed for Piezoelectric Transducers", International Conference on Electrical And Power Engineering(EPE 2014), Iasi, Romania, October 2014.

[8] COMSOL Multiphysics v3.5 and v4.1, Multiphysics Modeling, Finite Element Analysis and Engineering Simulation Software () 1998-2013 COMSOLA

[9] "RF Controlled Metal and Deleterious Gas Detecting ROVER" Dr. Mallikarjun Mudda, Dr. Thangadurai N, World Journal of Engineering research and Technology, 4 (1), 221-229, 2017.

[10] “Application of System Engineering in Election Voting System"Dr. Mallikarjun Mudda, Dr. Sruthi Bhargav N, International Journal of Engineering \& Technology-UAE, 7(2.16) 102-106, issue 16, 2018(Scopus Indexed).
[11] "Automatic Solar Grass Cutter" Dr. Mallikarjun Mudda, Vishwa Teja, International Journal for Research in Applied Science \& Engineering TechnologyVolume 6, Issue IV, April 2018.

[12] "Smart helmet and intelligent bike system using RF technology" Dr. Mallikarjun Mudda, Mr. E Sandeep, International Journal of Basic and Applied Research, P-ISSN 22493352, E-ISSN 22780505, 2018.

[13] "Distance Analysis Using HC-SR04" Dr. Mallikarjun Mudda, G.Prathyusha, JETIR November 2018, Volume 5, Issue 11, 2018.

[14] "HAPTIC ARM FOR PARALYSED PEOPLE" Dr. Mallikarjun Mudda, A Rakesh, K Gayathri, International Journal of Research and Analytical Reviews (IJRAR), Volume 6, Issue 1March 2019.

[15] "CONTROLLING SPEED OF MAGLEV USING GAP ANALYSIS" Dr. Mallikarjun Mudda, G Prathyusha, A Akshay, International Journal of Research and Analytical Reviews (IJRAR), Volume 6, Issue 1March 2019.

[16] "Assistance for Blind through Audio Command" Dr. Mallikarjun Mudda, Lavan Kumar, International Journal of Science and Research (IJSR) Volume 8 Issue 3, March 2019.

[17] "RESERVATION BASED SMART PARKING SYSTEM" Dr. Mallikarjun Mudda, Thrived Kumar, International Journal of Research and Analytical Reviews, 2019 IJRAR March 2019, Volume 6, Issue 1.

[18] "Voice-Assisted Blind Spot Detection for Vehicles with Accident Detection”Dr. Mallikarjun Mudda, G Sai Aishwarya, International Journal for Research in Applied Science \& Engineering Technology (IJRASET), Volume 7 Issue IV, Apr 2019

[19] Goel, A., Bhujade, R.K. "A functional review, analysis and comparison of position permutation based image encryption techniques" (2020) International Journal of Emerging Technology and Advanced Engineering, 10 (7), pp. 97-99.

[20] Dubey, G.P., Bhujade, R.K. "Improving the performance of intrusion detection system using machine learning based approaches ", International Journal of Emerging Trends in Engineering Research, 2020, 8(9), pp. 4947-4951

[21] Goel, A., Bhujade, R., "A prototype model for image encryption using zigzig blocks in inter-pixel displacement of RGB value" International Journal of Advanced Trends in Computer Science and Engineering, 2020, 9(5), pp. 6905-6912

[22] Nwankwo, P.C. "An improved method for determining static bottom hole pressure in dry natural gas wells: A computer programming approach" (2020) International Journal of Emerging Technology and Advanced Engineering, 10 (5), pp. 171-175.

[23] Péné, A.D., Barro, F.I., Kamta, M., Bitjoka, L., Nkeng, G.E., Kapseu, C.'Theoretical study of a bifacial silicon solar cell front side illuminated: Magnetic field effect on the recombination velocities inducing the short circuit and limiting the open circuit "(2021) International Journal of Emerging Technology and Advanced Engineering, 11 (2),

[24] Sandoval-Ibarra, F., Arzate-Palma, V.H., Cárdenas-Castellón, S.D." Design of a fully-differential CMOS OTA foldedcascode for modulation",(2020) International Journal of Emerging Technology and Advanced Engineering, 10 (11), pp. 1-6. 